\title{
The bailout transseptal approach during valve-in-valve transcatheter aortic valve implantation with difficult crossing of the degenerated Mitroflow bioprosthetic valve
}

\author{
Damian Hudziak ${ }^{1}$ Andrzej Ochała², Radosław Gocoł', Michał Kozłowski², Wojciech Wojakowski² \\ 1 Department of Cardiac Surgery, Medical University of Silesia, Katowice, Poland \\ 2 Division of Cardiology and Structural Heart Diseases, Medical University of Silesia, Katowice, Poland
}

Correspondence to: Damian Hudziak, MD, PhD, Department of Cardiac Surgery, Medical University of Silesia, ul. Ziołowa 47, 40-635 Katowice, Poland, phone: +48323598644 , email: damhud@gmail.com Received: January 20, 2021. Revision accepted: March 2, 2021. Published online: March 12, 2021. Kardiol Pol. 2021; 79 (4): 473-474 doi:10.33963/KP.15871 Copyright by the Author(s), 2021
Valve-in-valve (ViV) transcatheter aortic valve implantation (TAVI) is an accepted treatment in patients with structural valve deterioration (SVD) who are not good candidates for reoperation. ${ }^{1,2}$ A 70-year-old man with New York Heart Association class III heart failure was admitted with SVD of a Mitroflow 21-mm bovine pericardial prosthesis implanted 7 years ago concomitantly with coronary artery bypass grafting. Transthoracic echocardiography showed severe valve stenosis (effective orifice area, $0.7 \mathrm{~cm}^{2}$; mean gradient, $62 \mathrm{~mm} \mathrm{Hg}$ ) and left ventricular ejection fraction of $50 \%$. Because of obesity (body mass index, $37.8 \mathrm{~kg} / \mathrm{m}^{2}$ ) and high perioperative mortality risk (EuroSCORE, 6.31\%), the Heart Team recommended transfemoral ViV TAVI after analyzing the multislice contrast computed tomography (FIGURE $1 A$ and $1 B$ ).

The procedure was attempted by the right femoral approach under local anesthesia. Despite the use of several catheters (Amplatz left 1, Amplatz left 2, Judkins right [JR], pigtail, internal mammary artery), as well as various straight tip wires (0.035' soft diagnostic, hydrophilic coated, coronary), the valve crossing was impossible. The patient was switched to general anesthesia, intubated, and transesophageal echocardiography was used. The right femoral vein was cannulated, and under the transesophageal echocardiography guidance, the atrial septal puncture was done. The transseptal sheath was introduced into the left atrium, the JR diagnostic catheter was pushed into the left ventricle
(FIGURE 1C), and the aortic valve was easily crossed anterogradely with a 0.035 ' straight tip diagnostic wire. After navigating the JR catheter into the ascending aorta, the soft guidewire was extended and snared using the snare introduced through the femoral artery. The JR catheter was pulled into the left ventricle along with the snare and guide catheter (FIGURE 1D-1E). It allowed retrograde placement of the stiff wire and implantation of a self-expanding Evolut R valve (FIGURE 1F). The procedure time was 3.5 hours. Control transthoracic echocardiography revealed mild paravalvular leak and reduced mean gradients to $13 \mathrm{~mm} \mathrm{Hg}$. The patient was discharged home without complications.

Although ViV TAVI is a widely accepted, less invasive alternative to reoperation in patients with SVD, it can pose some technical procedural challenges. Usually, crossing of the prosthesis is straightforward because in many cases, there is some degree of regurgitation and less calcifications than in the native valve which makes the leaflet opening more symmetrical. In our case, we found the crossing using variety of catheters and wires impossible. Antegrade aortic valve crossing via the transseptal access is a solution in such cases. This approach was used by Cribier et $\mathrm{al}^{3}$ during the first successful TAVI. Alternatively to our method, snaring of the retrograde wire can be done in the ascending aorta with a snare introduced by the antegrade catheter. Other complications associated with ViV TAVI are coronary artery obstruction, elevated 

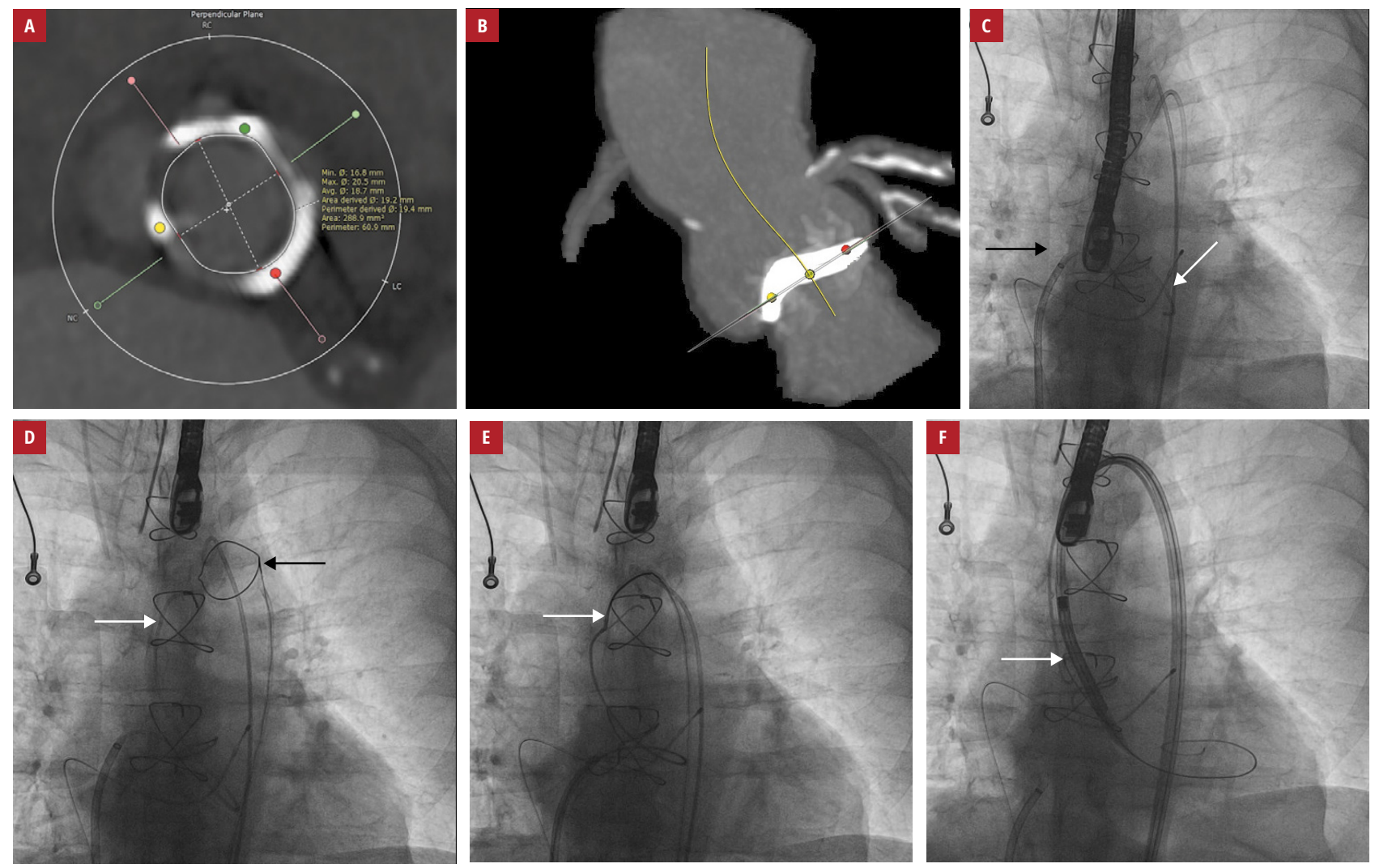

FIGURE 1 A - multislice contrast computed tomography of implanted bioprosthesis and the ascending aorta, the short axis view; B - multislice contrast computed tomography of implanted bioprosthesis and ascending aorta, the long axis view; $\mathbf{C}$ - fluoroscopy of the transeptal sheath (black arrow) in the left atrium and the diagnostic catheter (white arrow) in the left ventricle; D - fluoroscopy of the diagnostic catheter (white arrow) in the ascending aorta after crossing the bioprosthesis aortic valve and the snare (black arrow) introduced through the femoral artery; $\mathbf{E}$ - fluoroscopy of the snared antegrade wire (arrow) in the ascending aorta; $\mathbf{F}$ - fluoroscopy of the self-expandable valve (Evolut R; arrow) in the implantation position

postprocedural gradient, and malposition. ${ }^{2,4}$ According to Bapat et al, ${ }^{5}$ careful procedure planning includes type, size, true stent internal diameter, and fluoroscopic appearance of the degenerated bioprosthesis. Moreover, selection of the appropriate size and model of the new transcatheter heart valve is important for successful implantation and to reduce complications.

\section{ARTICLE INFORMATION}

\section{CONFLICT OF INTEREST None declared}

OPEN ACCESS This is an Open Access article distributed under the terms of the Creative Commons Attribution-NonCommercial-NoDerivatives 4.0 International License (CC BY-NC-ND 4.0), allowing third parties to download articles and share them with others, provided the original work is properly cited, not changed in any way, distributed under the same license, and used for noncommercial purposes only. For commercial use, please contact the journal office at kardiologiapolska@ptkardio.pl.

HOW TO CITE HudziakD, Ochała A, GocołR, et al. The bailout transseptal approach during valve-in-valve transcatheter aortic valve implantation with difficult crossing of the degenerated Mitroflow bioprosthetic valve. Kardiol Pol. 2021; 79: 473-474. doi:10.33963/KP.15871

\section{REFERENCES}

1 Wenaweser P, Buellesfeld L, Gerckens U, Grube E. Percutaneous aortic valve replacement for severe aortic regurgitation in degenerated bioprosthesis: the first valve in valve procedure using the Corevalve Revalving system. Catheter Cardiovasc Interv. 2007; 70: 760-764.

2 Paradis JM, Del Trigo M, Puri R, Rodés-Cabau J. Transcatheter valve-in-valve and valvein- ring for treating aortic and mitral surgical prosthetic dysfunction. J Am Coll Cardiol. 2015; 66: 2019-2037.
3 Cribier A, Eltchaninoff $\mathrm{H}$, Bash $\mathrm{A}$, et al. Percutaneous transcatheter implantation of an aortic valve prosthesis for calcific aortic stenosis: first human case description. Circulation. 2002; 106: 3006-3008.

4 Dvir D, Webb J, Brecker S, et al. Transcatheter aortic valve replacement for degenerative bioprosthetic surgical valves: results from the global valve in-valve registry. Circulation. 2012; 126: 2335-2344.

5 Bapat V. Technical pitfalls and tips for the valve-in-valve procedure. Ann Cardiothorac Surg. 2017; 6: 541-552. 